\title{
Radiographic Features of Rhupus Arthropathy
}

\author{
Jun Nakamura, Takao Nagashima, Yoichiro Akiyama and Seiji Minota
}

Key words: rheumatoid arthritis, systemic lupus erythematosus

(Intern Med 52: 2837, 2013)

(DOI: 10.2169/internalmedicine.52.1454)

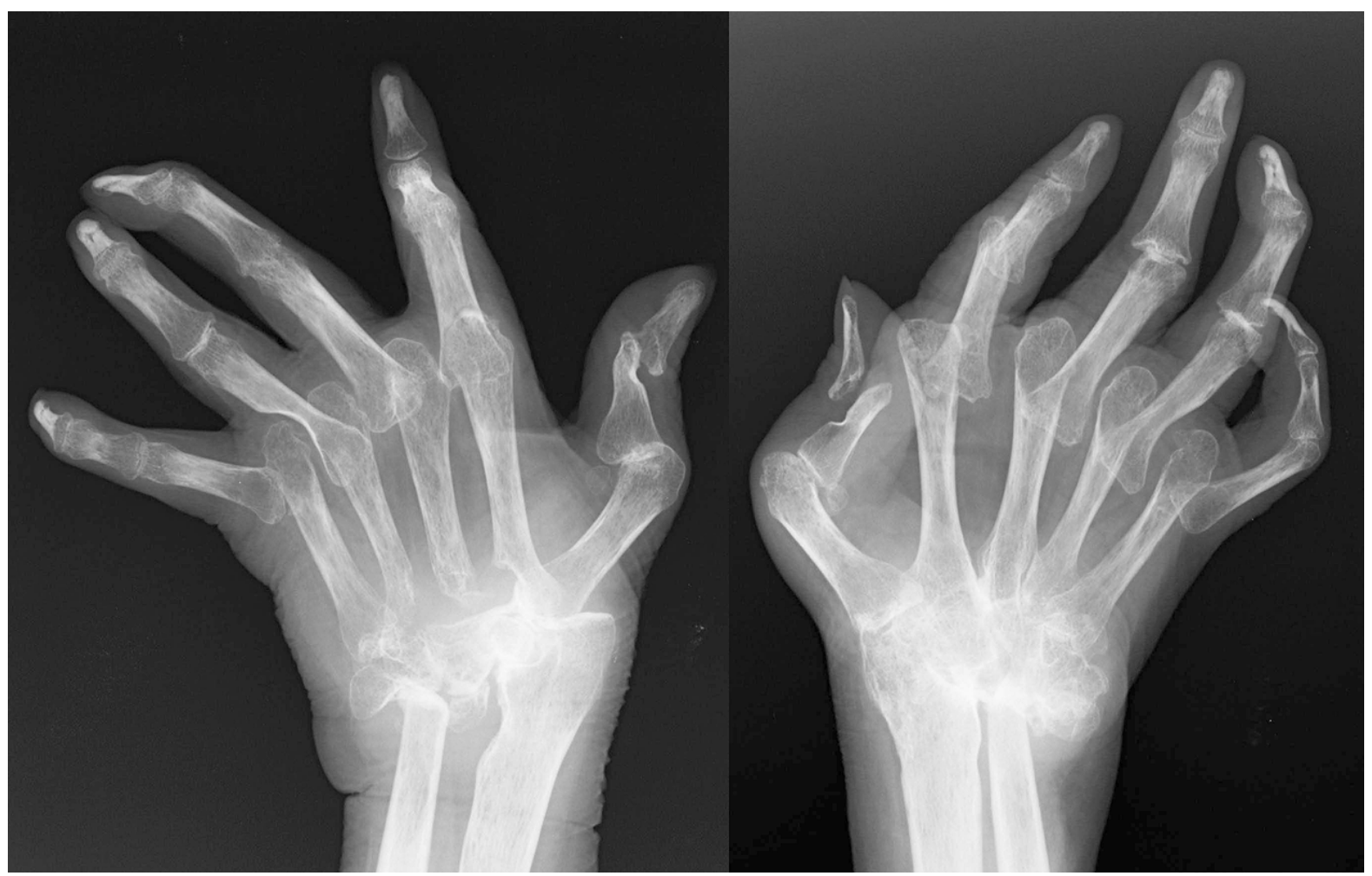

Picture.

A 66-year-old woman was diagnosed with rheumatoid arthritis (RA) at 30 years of age and developed systemic lupus erythematosus (SLE) at 37 years of age. The diagnosis of SLE was made based on the presence of leukopenia, positive antinuclear, anti-DNA, anti-ribonucleoprotein (RNP) and anti-Sm antibodies and membranous-type lupus nephritis. Her RA hemagglutination titer was 1:320. Sjögren's syndrome was also diagnosed because anti-SSA antibodies and a lip biopsy were positive. A recent radiograph of the patient's hands showed severe bilateral ulnar dislocation of the fingers without bone erosions of the metacarpophalangeal joints. The carpal bones were almost completely resorbed on the left side and fused on the right side (Picture). The bilateral metatarsophalangeal joints were also dislocated laterally without bone erosions. A cervical spine radiograph revealed severe anterior atlantoaxial subluxation. The level of anticitrullinated peptide antibodies was $5.1 \mathrm{U} / \mathrm{mL}$ (normal <4.5). Fulfillment of the criteria for both RA and SLE is sometimes called "rhupus."

The authors state that they have no Conflict of Interest (COI).

Division of Rheumatology and Clinical Immunology, Department of Medicine, Jichi Medical University, Japan Received for publication July 28, 2013; Accepted for publication July 31, 2013

Correspondence to Dr. Takao Nagashima, naga4ma@jichi.ac.jp

(C) 2013 The Japanese Society of Internal Medicine Journal Website: http://www.naika.or.jp/imonline/index.html 